\title{
Evaluation of Additive Manufacturing Parts Machinability using Automated GMAW ER70S-6 with Nodular Cast Iron
}

\author{
Augusto Dttmann ${ }^{1}$, Jefferson de Oliveira Gomes ${ }^{2}$ \\ ${ }^{1}$ Department of Mechanical Engineering, Aeronautics Institute of Technology (ITA), Marechal \\ Eduardo Gomes 50, São José dos Campos 12228-900, Brazil (augusto@ita.br) ORCID 0000- \\ 0003-2264-8572; 'Department of Mechanical Engineering, Aeronautics Institute of \\ Technology (ITA), Marechal Eduardo Gomes 50, São José dos Campos 12228-900, Brazil \\ (gomes@ita.br) ORCID 0000-0002-6004-799X
}

\begin{abstract}
Through additive manufacturing is possible to obtain products with few material waste, low production time and great flexibility in geometry. In recent years, the application of arc welding processes has been studied as additive manufacturing techniques for metals. When compared to laser welding processes, they have low equipment cost, high deposition rate, however a low surface quality. This work proposes to study the machinability of additive manufacturing parts using automated GMAW. The deposition was carried out using a robotic arm, using ER70S6 ' wire with a substrate of nodular cast iron. Two deposition strategies were carried out, one alternating the passes directions and the other one depositing in the same direction. The machining process used was milling in a three axis machining center. The deposition strategy had an influence on the parts surface finish after machining, as well as on the tool life.
\end{abstract}

Author Keywords. Additive Manufacturing, WAAM, Machining, GMAW.

Type: Research Article

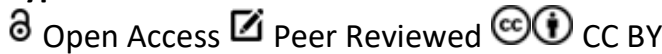

\section{Introduction}

Additive manufacturing (AM) is the production process that consists of layer-by-layer deposition (Jiménez et al. 2019; Zhu et al. 2020). This process is also known as 3D printing, it allows the production of complex geometries and decreases the production cost and the production cycle time, mainly for small batches (Zhu et al. 2020).

Researchers have been studying AM applications for over 30 years (Beaman and Deckard 1990), however, only with the recent advances in technology it is possible to achieve parts in different materials, high density and better finishes (Beaman and Deckard 1990). Currently, there is a great diversity of materials that can be used with additive manufacturing, there are applications with metals, polymers, biomaterials and composites (Zhu et al. 2020). Despite its complexity, metallic AM applications are a reality in the aerospace, medical, automotive, energy and other fields (Wang et al. 2020; Fasel et al. 2020; Delic and Eyers 2020; da Silva et al. 2020). The most common deposition processes with metals are laser beam melting (LBM), electron beam melting (EBM), and laser metal deposition (LMD), all generally based on metal powders as feedstock (Herzog et al. 2016).

AM processes using powder as feedstock provide parts with a good surface finish and allows to produce parts with more complex geometries (da Silva et al. 2020), however, the costs are high and the production time for larger dimensions is very long (DebRoy et al. 2018). As an alternative to these processes there is a wire arc additive manufacturing (WAAM) (DebRoy et al. 2018; da Silva et al. 2020). 
These processes are based on welding with gas protection as tungsten arc (GTA) and the variants of gas metal arc (GMA). WAAM provides a high deposition rate, but the quality of internal integrity and surface finish is reduced. The deposition rate with this process for aluminum and steel is from $1 \mathrm{~kg} / \mathrm{h}$ to $4 \mathrm{~kg} / \mathrm{h}$, however it is possible to achieve rates above 10 $\mathrm{kg} / \mathrm{h}$, but the dimensional accuracy is low (Williams et al. 2016). As a disadvantage, there is the residual stress inserted in the part due to the shrinkage during cooling, which is greater along the direction of position (Liu et al. 2020). Distortions in dimensions result in poor tolerance quality while residual stress affects part performance (Colegrove et al. 2014). Thus, post-processing on the workpiece produced with WAAM is necessary in order to meet the desired specifications such as surface finish and geometric precision (Ding et al. 2011).

According to Ding et al (2011), for the industry it is necessary to study the pieces machining produced by $A M$, in order to make the process more interesting. The author also points out that the main points of interest are the tool life assessment and the temperature gradient impact on the microstructure and roughness of the final surface.

This work proposes to study the machinability of additive manufacturing parts using automated GMAW. The deposition was carried out using a robotic arm, using ER70S-6' wire with a substrate of Nodular Cast Iron.

\section{Materials and Methods}

The experiment followed the flowchart, presented in Figure 1. The first step was to deposit the weld beads using an automated source from Lincoln Electric model S500.

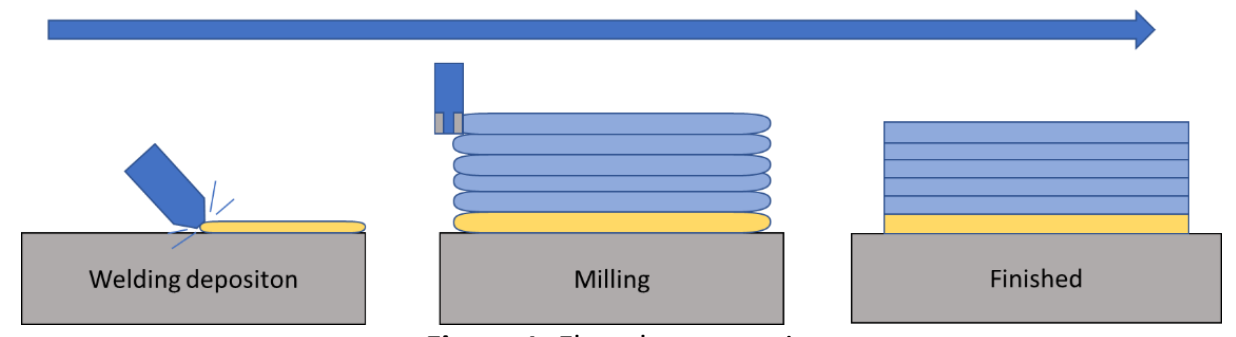

Figure 1: Flowchart experiment

\subsection{Welding deposition}

The deposition was carried out using a robotic arm Kuka KR 16 and ER70S-6' wire with a substrate of Nodular Cast Iron. Two deposition strategies were carried out, one alternating the passes directions and the other one depositing in the same direction (Figure 1). The Welding wire chemical composition is show in Table 1 . The welding parameters were defined in pre-tests, Table 2 and Table 3.

\begin{tabular}{|c|c|c|c|c|c|c|c|c|c|}
\hline $\mathbf{C}$ & $\mathbf{M n}$ & $\mathbf{S i}$ & $\mathbf{P}$ & $\mathbf{S}$ & $\mathbf{C r}$ & $\mathbf{N i}$ & $\mathbf{M o}$ & $\mathbf{T i}$ & $\mathbf{C u}$ \\
\hline $0.06-$ & $1.40-$ & $0.80-$ & $<=0.025$ & $<=0.025$ & $<=0.15$ & $<=0.15$ & $<=0.15$ & $<=0.15$ & $<=0.50$ \\
0.14 & 1.60 & 1.00 & & & & & & &
\end{tabular}

Table 1: Welding wire chemical composition(\%)

\begin{tabular}{|c|c|}
\hline \multicolumn{2}{|c|}{ Welding Parameters } \\
\hline Welding current [A] & 170 \\
\hline Welding voltage [V] & 20 \\
\hline DBCP [mm] & 16 \\
\hline Feed speed [m/min] & 3.5 \\
\hline Welding speed [cm/min] & 40 \\
\hline Shielding gas & $\mathrm{Ar}-25 \% \mathrm{CO}_{2}$ \\
\hline Gas flow & 15 \\
\hline
\end{tabular}

Table 2: Welding parameters 


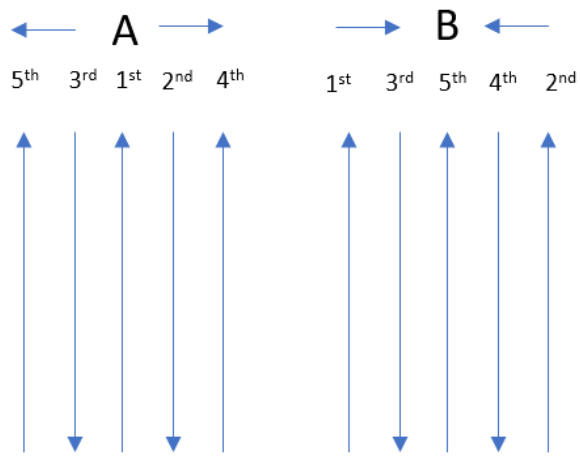

Figure 2: Pass sequence of the two deposition strategies

The distance between passes is shown in Table 3. The dimensions of the nodular cast iron workpiece are $200 \times 175 \times 15 \mathrm{~mm}$ (Figure 3).

\begin{tabular}{|c|c|c|}
\hline & Overlap (\%) & Offset from centerline (mm) \\
\hline ER 70S-6 / Buttering layer & 37,5 & 5 \\
\hline ER 70S-6 & 36 & 4.5 \\
\hline
\end{tabular}

Table 3: Welding parameters

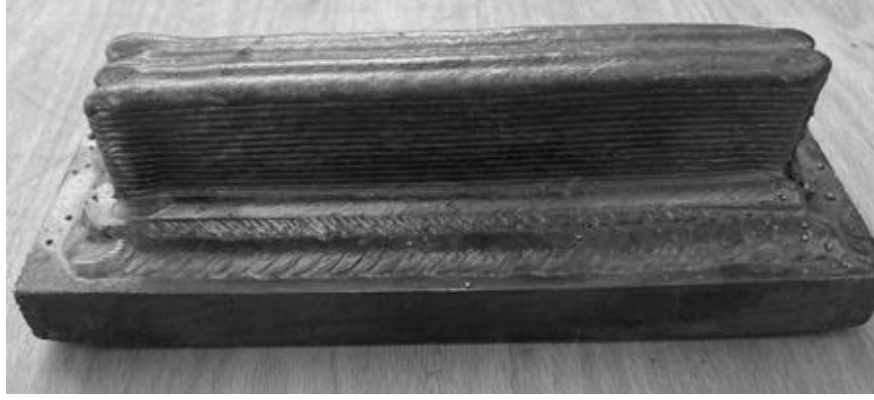

Figure 3: Final workpiece

\subsection{Machining}

The machining process used was milling in ROMI DCM 620-5x and the insert was Sandvick R390-11 T3 10M-KH 3040, Table 4. The machining parameters were defined in pre-tests and is shown in Table 5.

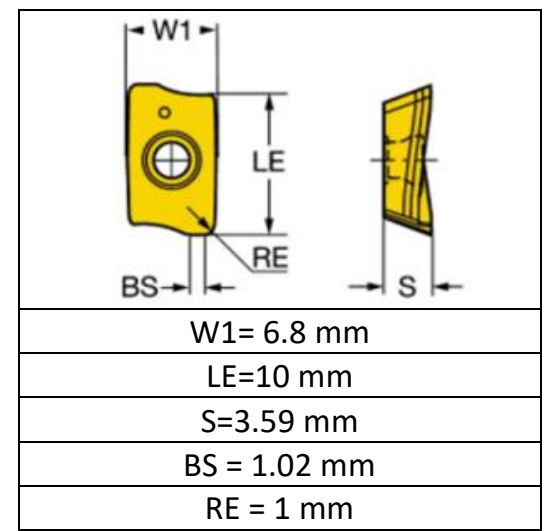

Table 4: The sample form of cutting tool

\begin{tabular}{|c|}
\hline$f_{z}=0.12 \mathrm{~mm}$ \\
\hline$V_{c}{ }^{1}=175 \mathrm{~m} / \mathrm{min}$ \\
\hline$V_{c}{ }^{1}=200 \mathrm{~m} / \mathrm{min}$ \\
\hline$V_{c}{ }^{1}=250 \mathrm{~m} / \mathrm{min}$ \\
\hline
\end{tabular}

Table 5: Cutting parameters 
Machining forces were measured by using Kistler's piezoelectric platform, with integration according to Figure 4. For the acquisition of the machining force, data were collected with the platform. In order to monitor the increase in machining force with the tool wear, the force measurements were performed at each stop of wear measurement and compared with the force measured with the tool in new state. For each acquisition round, a new file was created in the system's interface software Dynoware Type 2825-D-02 (Figure 6). To ensure a wide range of different load intensities, all acquisitions were performed with a measuring range of $8000 \mathrm{~N}$ per amplifier channel. The machined surface was analyzed with the Cyber CT 100.

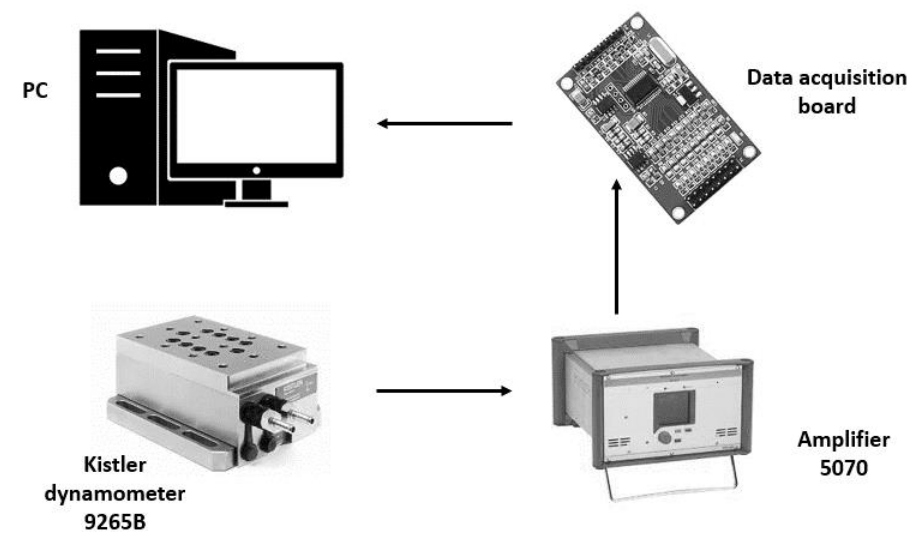

Figure 4: Integration of the force acquisition system

The most significant forces for the experiment were those oriented in the $X$ and $Y$ directions. Since the cutting force reflects the power required by the machining center, the amplitude in the three directions was considered. The analyzed force consisted in the resultant of the force vectors in the $\mathrm{X}, \mathrm{Y}$ and $\mathrm{Z}$ directions calculated by Equation (1).

$$
F_{R}=\sqrt{F_{X}^{2}+F_{Y}^{2}+F_{Z}^{2}}
$$

\section{Results and Discussion}

\subsection{Microstructure characterization}

Figure 5 shows the profiles obtained with each deposition strategies in the first stage of the study. With strategy $B$, the profile of the final structure showed an elevation in the central part when compared to strategy $A$.

This buildup in the central region in the wall with strategy $B$ represents a difference of $5 \%$ in the final height.

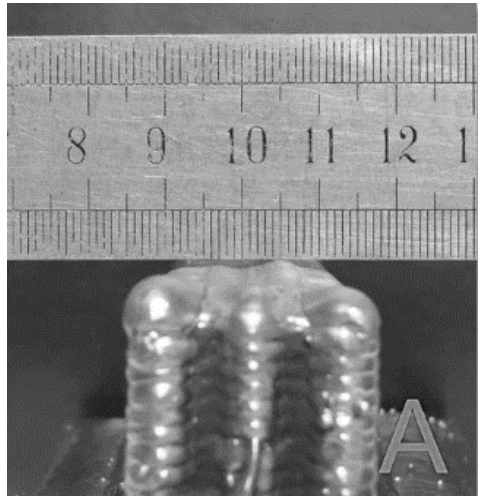

(a)

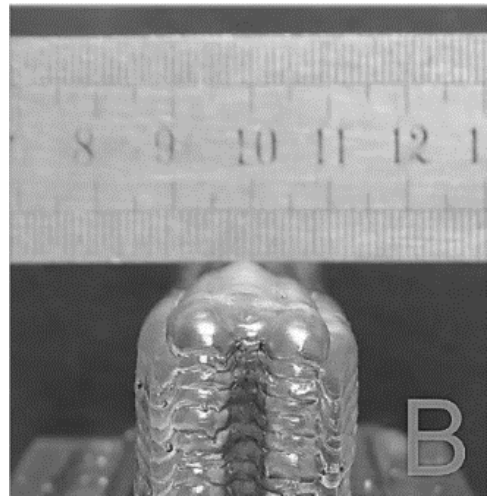

(b)

Figure 5: (a) Profile obtained with strategy A. (b) profile obtained with strategy B 
Figure 6 shows the walls with strategy $A$ and $B$. The pieces showed a waviness of $603 \pm 147$ $\mu \mathrm{m}$ for strategy $A$ and $631 \pm 178 \mu \mathrm{m}$ for strategy $B$. The measurements were performed in the profile of the cross section. This result is close to the obtained in Lopes et al. (2020) when used the same deposition technique.

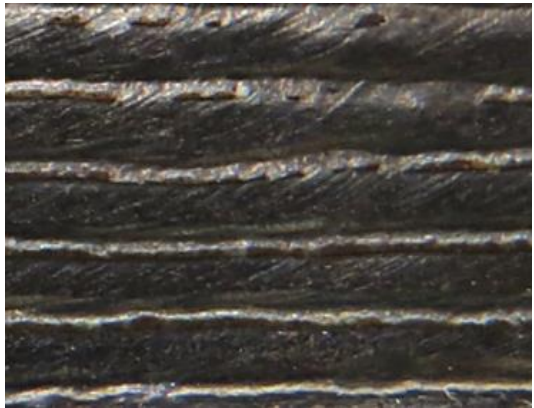

(a)

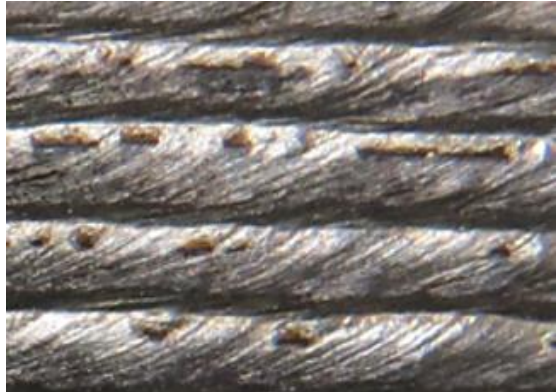

(b)

Figure 6: Wall obtained with strategies A (a) e B (b)

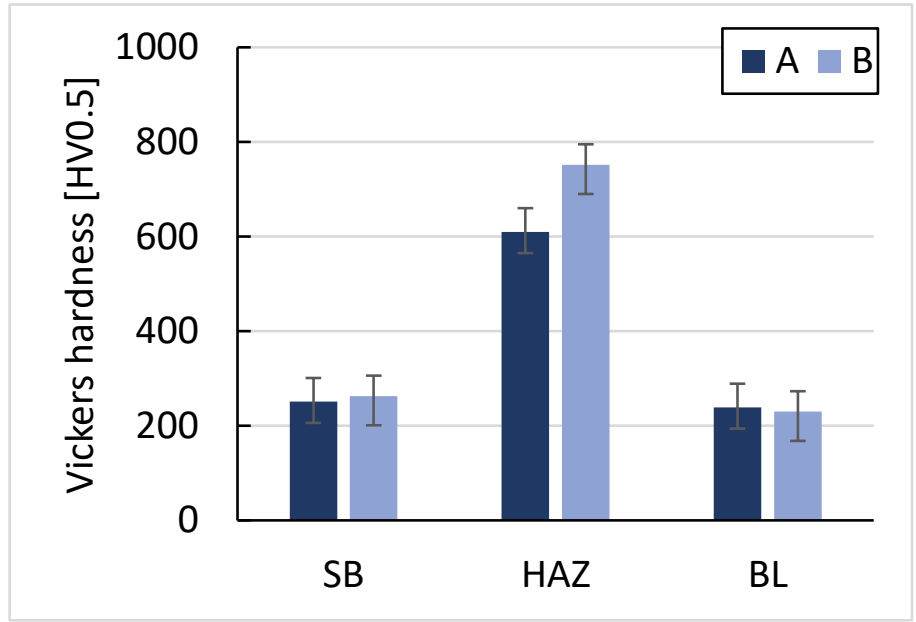

Figure 7: Hardness fore substrate (SB), heat-affected zone (HAZ) and buttering layer (BL)

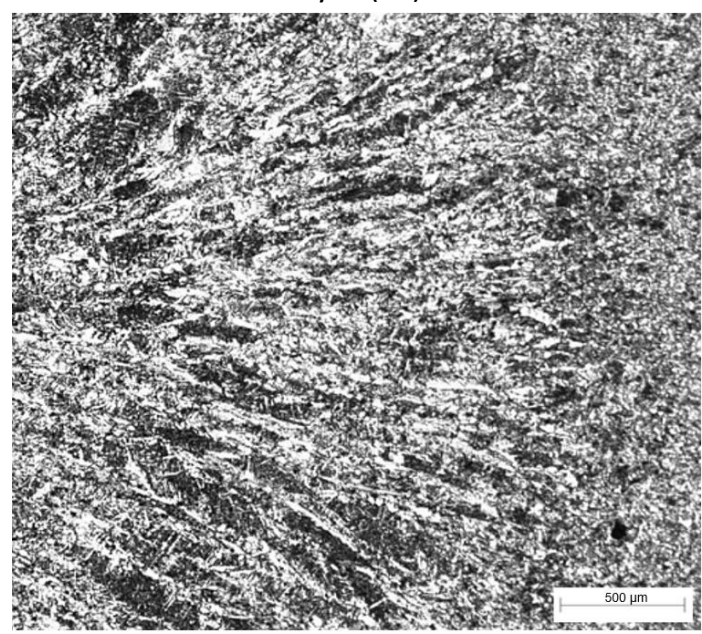

Figure 8: Microstructure of Prismatic Geometry

Figure 8 shows the microstructure of prismatic geometry, which exhibits a variation between coarse and fine recrystallization caused due to complex cycle. These cycles are usually complex (Thijs et al. 2010). It is possible to see that there is a greater presence of coarse grains when compared to final. The microhardness of this region was $221 \mathrm{HV}$. 
When measuring the micro hardness in the thermally affected region $(\mathrm{HZ})$ of the parts produced, it appears that strategy $B$ generated a greater hardness (Figure 7). This can be explained by a more homogeneous heat dissipation with strategy $A$ when compared to $B$. Thus, the entry of heat and solidification conditions with $B$ provided a greater formation of martensitic structures.

\subsection{Deformation}

After the metal wall deposition, a deformation was verified in the final piece (Figure 9). This deformation was caused by the shrinkage of the part due to the non-homogeneous heating of the workpiece during welding and consequent appearance of residual stresses. The average difference in the final size was $4 \mathrm{~mm}$ for strategy $A$ and $6 \mathrm{~mm}$ for strategy $B$. In this way, strategy $B$ can insert a greater residual stress in the final piece.

The way the part was deformed suggests that the residual stress was mostly concentrated in the deposition direction. This result corroborates to the data presented by Liu et al. (2020).

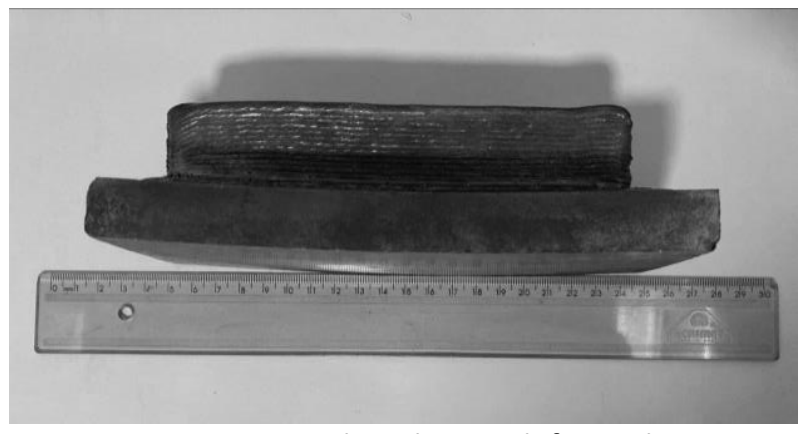

Figure 9: Final workpiece deformed

The interface between the substrate and the deposited material can concentrate strong residual stress peaks up to $500 \mathrm{MPa}$ (Martina et al. 2016). The author also identified that rolling between passes can reduce residual stress peaks by up to $300 \mathrm{MPa}$.

\subsection{Force and tool life}

When monitoring tool life according to the method presented in the previous section, we sought to analyze its influence on machinability. Figure 10 shows the resulting cutting force as a function of the cutting length for the three proposed cutting speeds.

The cutting speed that generated the lowest cutting force was $250 \mathrm{~m} / \mathrm{min}$, however it generated the largest flank wear (Figure 10).

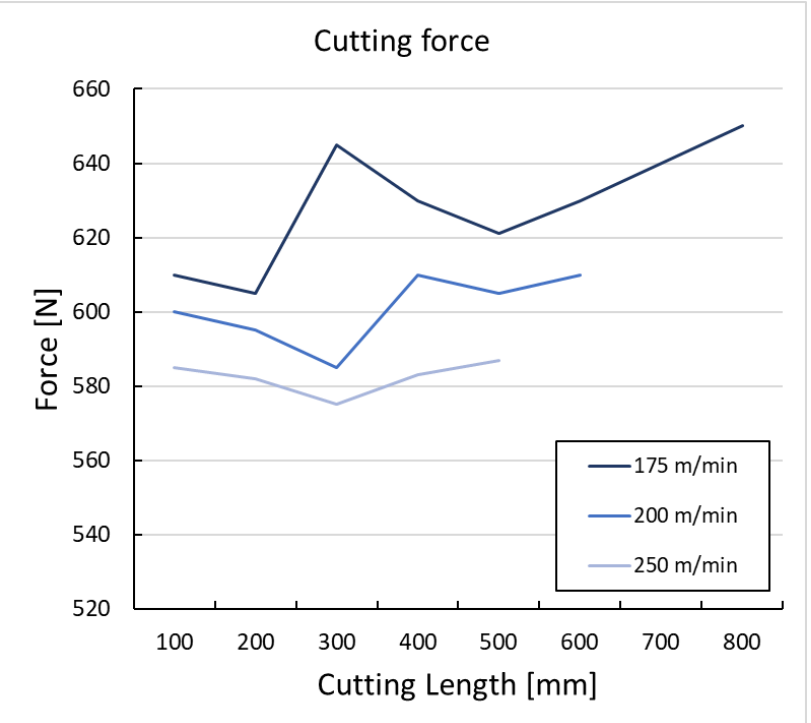

Figure 10: Cutting force $x$ cutting length 
The behavior of the resultant from cutting force, obtained from the variation of the cutting speed is in accordance with that established in the literature. An increase in cutting speed tends to decrease the specific cutting pressure, thereby decreasing the force (Machado et al. 2011). This behavior may indicate the absence of built up cutting edge (BUE).

When analyzing Figure 10 and Figure 11, it is possible to identify an increase in the cutting force with tool wear. This effect can be explained due to the increased friction between tool/part, which generates an increase in the specific cutting pressure (Machado et al. 2011).

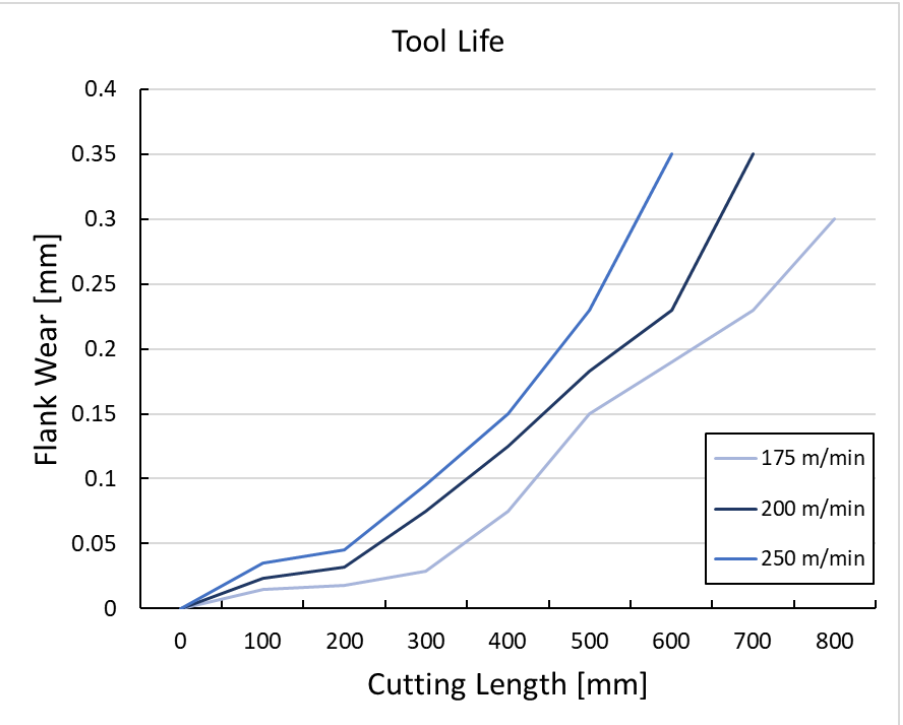

Figure 11: Flank wear $x$ cutting length

The speed came to an end with a wear of $0.3 \mathrm{~mm}$ after $550 \mathrm{~mm}$. The analyzed results are in agreement with Ghani, Choudhury, and Husni (2002).

\subsection{Roughness}

The roughness of a surface is made up of fine irregularities or micro geometric errors resulted by the inherent action of the cutting process (Machado et al. 2011).

The roughness of the surface measured according to the method showed in the previous section is presented as a function of the cutting length in Figure 12. The cutting speed that showed the least roughness was a speed of $250 \mathrm{~m} / \mathrm{min}$. Throughout the tool use and with increased wear, the roughness increases. This effect can be easily identified by analyzing Figure 11 and Figure 12 together. It was also possible to identify that the surface finish at this speed does not show any discrepancy along its surface (Figure 13). A better finish is expected with higher speeds, this result was also obtained by Xiong et al. (2020).

According to the literature, the roughness in the front milling can be calculated by Equation (2), where $r_{e}$ is the tool tip radius and $f_{z}$ is the feed.

$$
R_{a}=\frac{r_{\varepsilon}-\sqrt{r_{\varepsilon}^{2}-\left(\frac{f_{z}}{2}\right)^{2}}}{2}
$$

Thus, the roughness is directly proportional to the tool tip radius, which increases with wear. 


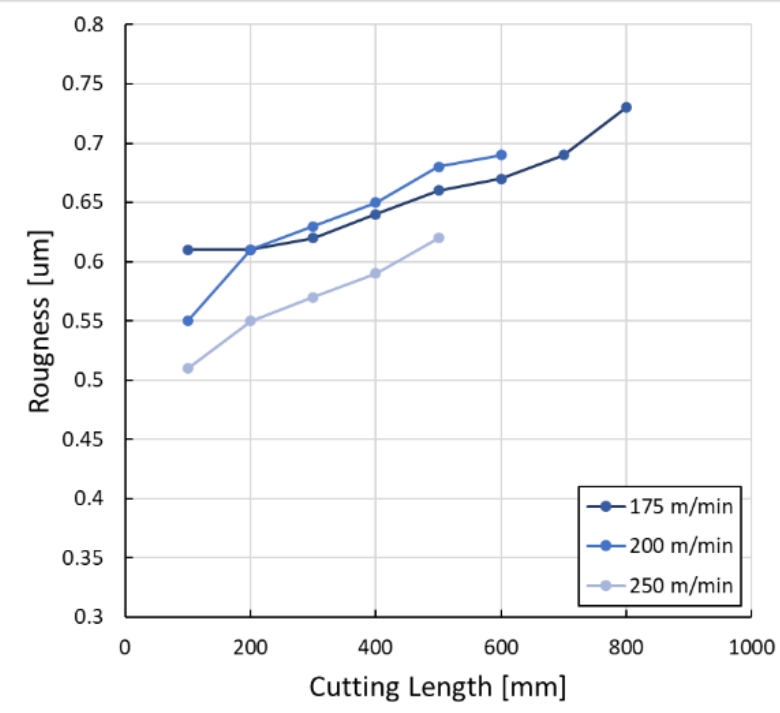

Figure 12: Flank wear vs. surface roughness at different speeds

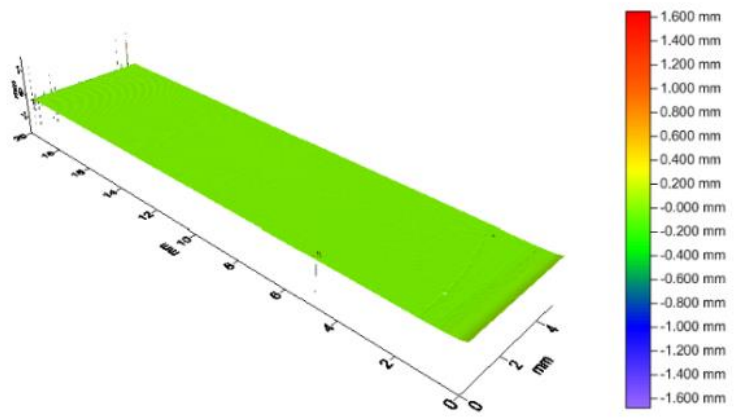

Figure 13: Surface roughness for $V_{c}=250 \mathrm{~m} / \mathrm{min}$

\section{Conclusion}

This work proposes to study the machinability of additive manufacturing parts using automated GMAW. After performing the tests, measuring the results, and analyzing the data, it is possible to make the following conclusions:

\subsection{Deposition}

- Welding parameter envelop was established. The robustness of this envelope was proved by the deposition of ten prismatic geometries pieces and no visual defects were found.

- The most important parameter to deposit a prismatic geometry is the lateral overlap.

- The way the part was deformed suggests that the residual stress was mostly concentrated in the direction of deposition.

- Strategy B can insert a greater residual stress in the final piece.

\subsection{Machining}

- Greater number of pores in the deposited wall were found with strategy B deposition.

- The cutting force decreased with increasing cutting speed.

- The force's behavior may indicate the absence of built up cutting edge (BUE).

- The speed of flank wear increased with increasing speed. 
- Both deposition strategies showed a good surface finish, but strategy A showed a higher quality.

- The best roughness obtained was $0.51 \mu \mathrm{m}$ with a speed of $250 \mathrm{~m} / \mathrm{min}$. This result was obtained with the tool in its new state.

\section{References}

Beaman, J. J., and C. R. Deckard. 1990. Selective laser sintering with assisted powder handling. US4938816A, filed September 5, 1989, and issued July 3, 1990. https://patents.google.com/patent/US4938816A/en.

Colegrove, P. A., F. Martina, M. J. Roy, B. A. Szost, S. Terzi, S. W. Williams, P. J. Withers, and D. Jarvis. 2014. "High pressure interpass rolling of wire + Arc Additively Manufactured titanium components". Advanced Materials Research 996: 694-700. https://doi.org/10.4028/www.scientific.net/AMR.996.694.

da Silva, L. J., D. M. Souza, D. B. de Araújo, R. P. Reis, and A. Scotti. 2020. "Concept and validation of an active cooling technique to mitigate heat accumulation in WAAM". International Journal of Advanced Manufacturing Technology 107, no. 5-6: 2513-23. https://doi.org/10.1007/s00170-020-05201-4.

DebRoy, T., H. L. Wei, J. S. Zuback, T. Mukherjee, J. W. Elmer, J. O. Milewski, A. M. Beese, A. Wilson-Heid, A. De, and W. Zhang. 2018. "Additive manufacturing of metallic components - Process, structure and properties". Progress in Materials Science 92: 112-224. https://doi.org/10.1016/j.pmatsci.2017.10.001.

Delic, M., and D. R. Eyers. 2020. "The effect of additive manufacturing adoption on supply chain flexibility and performance: An empirical analysis from the automotive industry". International Journal of Production Economics 228: 107689. https://doi.org/10.1016/j.ijpe.2020.107689.

Ding, J., P. Colegrove, J. Mehnen, S. Ganguly, P. M. S. Almeida, F. Wang, and S. Williams. 2011. "Thermo-mechanical analysis of Wire and Arc Additive Layer Manufacturing process on large multi-layer parts". Computational Materials Science 50, no. 12: 3315-22. https://doi.org/10.1016/j.commatsci.2011.06.023.

Fasel, U., D. Keidel, L. Baumann, G. Cavolina, M. Eichenhofer, and P. Ermanni. 2020. "Composite additive manufacturing of morphing aerospace structures". Manufacturing Letters 23: 85-88. https://doi.org/10.1016/j.mfglet.2019.12.004.

Ghani, A. K., I. A. Choudhury, and Husni. 2002. "Study of tool life, surface roughness and vibration in machining nodular cast iron with ceramic tool". Journal of Materials Processing Technology 127, no. 1: 17-22. https://doi.org/10.1016/S0924-0136(02)00092-4.

Herzog, D., V. Seyda, E. Wycisk, and C. Emmelmann. 2016. "Additive manufacturing of metals". Acta Materialia 117: 371-92. https://doi.org/10.1016/j.actamat.2016.07.019.

Jiménez, M., L. Romero, I. A. Dominguez, M. D. Espinosa, and M. Domínguez. 2019. "Additive manufacturing technologies: An overview about 3D printing methods and future prospects". Complexity: 9656938. https://doi.org/10.1155/2019/9656938.

Liu, C., C. H. Lin, J. F. Wang, J. X. Wang, L. J. Yan, Y. Luo, and M. Yang. 2020. "Residual stress distributions in thick specimens excavated from a large circular wire plus arc additive manufacturing mockup". Journal of Manufacturing Processes 56: 474-81. https://doi.org/10.1016/j.jmapro.2020.05.007.

Lopes, J. G., C. M. Machado, V. R. Duarte, T. A. Rodrigues, T. G. Santos, and J. P. Oliveira. 2020. "Effect of milling parameters on HSLA steel parts produced by Wire and Arc Additive 
Manufacturing (WAAM)". Journal of Manufacturing Processes 59: 739-49. https://doi.org/10.1016/j.jmapro.2020.10.007.

Machado, Á. R., A. M. Abrão, R. T. Coelho, and M. B. da Sillva. 2011. Teoria da usinagem dos materiais. $2^{\text {nd }}$ ed. Blucher.

Martina, F., M. J. Roy, B. A. Szost, S. Terzi, P. A. Colegrove, S. W. Williams, P. J. Withers, J. Meyer, and M. Hofmann. 2016. "Residual stress of as-deposited and rolled wire plus arc additive manufacturing Ti-6Al-4V components". Materials Science and Technology 32, no. 14: 1439-48. https://doi.org/10.1080/02670836.2016.1142704.

Thijs, L., F. Verhaeghe, T. Craeghs, J. V. Humbeeck, and J.-P. Kruth. 2010. "A study of the microstructural evolution during selective laser melting of Ti-6Al-4V". Acta Materialia 58, no. 9: 3303-12. https://doi.org/10.1016/j.actamat.2010.02.004.

Wang, J., C. M. Shao, Y. T. Wang, L. Y. Sun, and Y. J. Zhao. 2020. "Microfluidics for medical additive manufacturing". Engineering 6, no. 11: 1244-57. https://doi.org/10.1016/j.eng.2020.10.001.

Williams, S. W., F. Martina, A. C. Addison, J. Ding, G. Pardal, and P. Colegrove. 2016. "Wire + Arc Additive Manufacturing". Materials Science and Technology 32, no. 7: 641-47. https://doi.org/10.1179/1743284715y.0000000073.

Xiong, Y., W. Wang, Y. Shi, R. Jiang, C. Shan, X. Liu, and K. Lin. 2020. "Investigation on surface roughness, residual stress and fatigue property of milling in-situ TiB2/7050Al metal matrix composites". Chinese Journal of Aeronautics. https://doi.org/10.1016/j.cja.2020.08.046.

Zhu, J., H. Zhou, C. Wang, L. Zhou, S. Yuan, and W. Zhang. 2020. "A review of topology optimization for additive manufacturing: Status and challenges". Chinese Journal of Aeronautics. https://doi.org/10.1016/j.cja.2020.09.020. 